International Journal of Medical Sciences

ISSN 1449-1907 www.medsci.org 2006 3(2):29-34

Review

(C)2006 Ivyspring International Publisher. All rights reserved

\title{
Molecular Virology of Hepatitis C Virus (HCV): 2006 Update
}

\author{
Volker Brass ${ }^{1}$, Darius Moradpour ${ }^{2}$ and Hubert E. Blum ${ }^{1}$
}

1. Department of Medicine II, University of Freiburg, D-79106 Freiburg, Germany

2. Division of Gastroenterology and Hepatology, Centre Hospitalier Universitaire Vaudois, University of Lausanne, CH-1011

Lausanne, Switzerland

Corresponding address: Hubert E. Blum, M.D., Department of Medicine II, University of Freiburg, Hugstetter Strasse 55, D-79106 Freiburg, Germany. Tel. +49 761270 3403. Fax +49 761270 3610. E-mail: hubert.blum@uniklinik-freiburg.de

Received: 2005.12.30; Accepted: 2006.03.10; Published: 2006.04.01

Fascinating progress in the understanding of the molecular biology of hepatitis $\mathrm{C}$ virus (HCV) was achieved recently. The replicon system revolutionized the investigation of HCV RNA replication and facilitated drug discovery. Novel systems for functional analyses of the HCV glycoproteins allowed the validation of HCV receptor candidates and the investigation of cell entry mechanisms. Most recently, recombinant infectious HCV could be produced in cell culture, rendering all steps of the viral life cycle, including entry and release of viral particles, amenable to systematic analysis. In this review, we summarize recent advances and discuss future research directions.

Key words: helicase, hepatitis C virus, protease, polymerase, replicon

\section{Introduction}

The hepatitis $\mathrm{C}$ virus (HCV) belongs to the Flaviviridae family and is the only member of the Hepacivirus genus. $\mathrm{HCV}$ infection is a major cause of chronic hepatitis, liver cirrhosis, and hepatocellular carcinoma (HCC) worldwide [1]. Therapeutic options are improving but are still limited and a protective vaccine is not available to date. In $50 \%$ to $80 \%$ acute $\mathrm{HCV}$ infection persists and $4 \%$ to $20 \%$ of patients with chronic hepatitis C will develop liver cirrhosis within 20 years. In patients with liver cirrhosis, the risk to develop HCC is $1-5 \%$ per year. Current standard therapy is the combination of pegylated interferon- $\alpha$ (PEG-IFN- $\alpha$ ) and ribavirin. Depending on the HCV genotype and other factors, this strategy results in a sustained virologic response in $50-80 \%$ of patients [2-5]. However, many patients do not qualify for or do not tolerate standard therapy [6]. Therefore, more effective and better tolerated therapeutic strategies are urgently needed. The development of such strategies depends on a detailed understanding of the molecular virology of HCV infection.

The investigation of the HCV life cycle and pathogenesis has been complicated by the lack of efficient cell culture systems and small animal models. Nevertheless, significant progress could be made using heterologous expression systems, functional cDNA clones [7], the replicon system [8, 9], and functional HCV pseudoparticles [10, 11] (see refs. [12-14] for reviews). Most recently, a major milestone was the production of recombinant infectious HCV particles in cell culture [15-17]. The model systems, summarized in Table 1, are the current basis for the study of the HCV life cycle and the development of novel antiviral strategies.

Table 1. In vitro and in vivo models to study $\mathrm{HCV}$.

In vitro models

- Transient expression systems

- $\quad$ Stably transfected cell lines (constitutive / inducible expression)

- Infection of primary hepatocytes and established cell lines

- Retroviral pseudoparticles displaying functional HCV glycoproteins

- $\quad$ Replicons (subgenomic / full-length; selectable / transient)

- Recombinant infectious cell culture system

- $\quad$ Chimeric viruses (e.g., poliovirus - HCV)

- $\quad$ Related viruses (e.g., GBV-B in tamarin hepatocytes)

In vivo models

- Transgenic mice

- Immunodeficient mice / hepatocellular reconstitution models

- $\quad$ Chimpanzee (Pan troglodytes)

- Tree shrew (Tupaia belangeri chinensis)?

- $\quad$ Related viruses (e.g., GBV-B in tamarins) 
Figure 1. Life cycle of HCV. The steps of the viral life cycle are depicted schematically. The topology of HCV structural and nonstructural proteins at the endoplasmic reticulum (ER) membrane is shown. HCV RNA replication occurs in a specific membrane alteration, the membranous web (MW). IRES-mediated translation and polyprotein processing as well as membranous web formation and RNA replication, illustrated here as separate steps for simplicity, may occur in a tightly coupled manner.

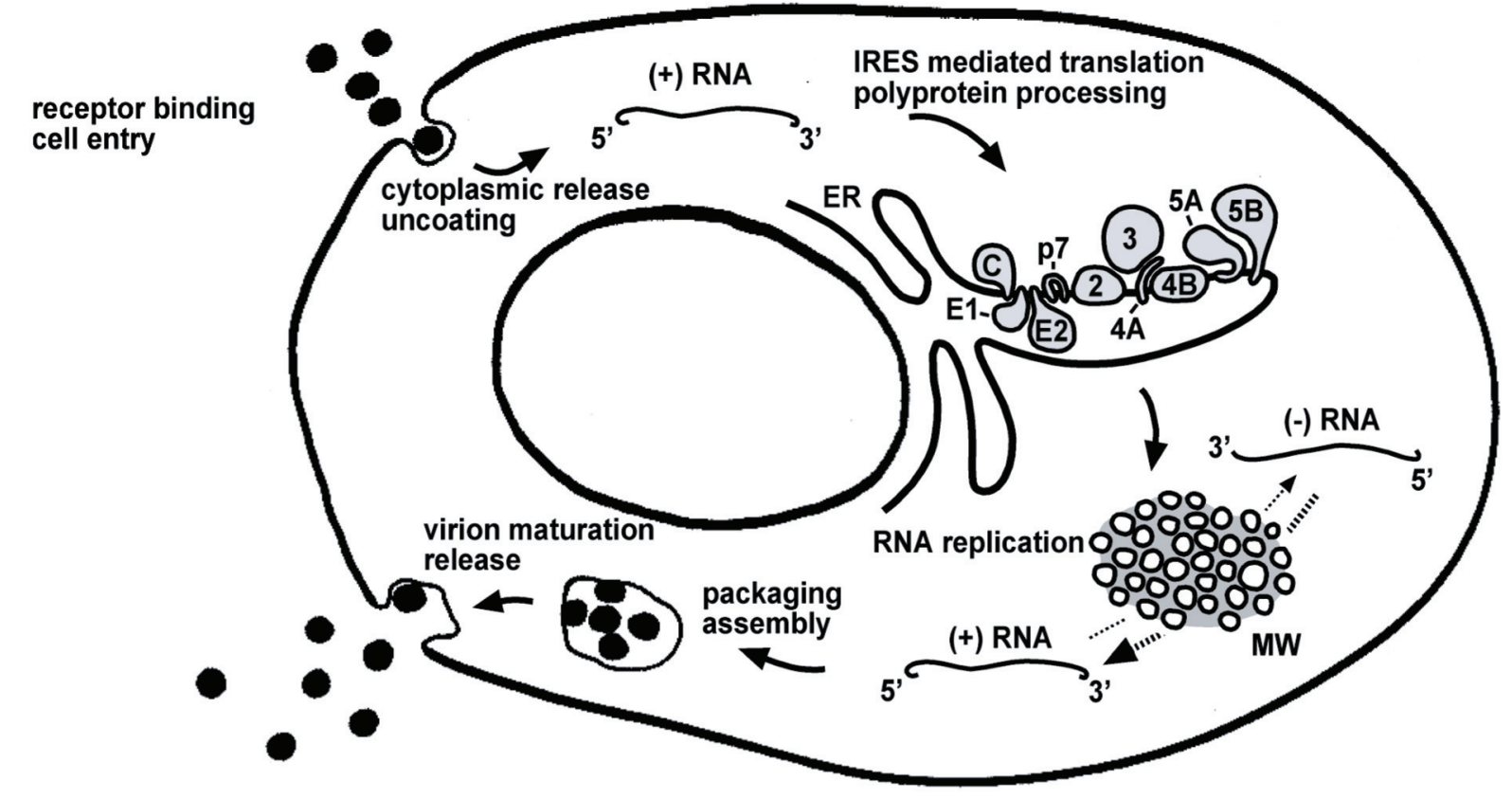

\section{The replicon system}

For many years, $\mathrm{HCV}$ research was hampered by the extremely restricted host range and the inefficiency of in vitro models based on the incubation of cells in culture with HCV particles. Therefore, the establishment of a replicon system for HCV was a milestone in HCV research $[8,18]$. The prototype subgenomic replicon utilized a particular HCV genotype $1 \mathrm{~b}$ clone termed Con 1 . In this system, the structural region was replaced by the sequence encoding the neomycin phosphotransferase gene resulting in G418 resistance. Expression of the nonstructural proteins is directed by a heterologous encephalomyocarditis virus (EMCV) internal ribosomal entry site (IRES) downstream of the neomycin phosphotransferase gene. After transfection into the human HCC cell line Huh-7 G418 resistant colonies contain selfreplicating HCV RNA. Critical for the usefulness of this system was the identification of specific amino acid substitutions, i.e., cell culture-adaptive changes, that increased the efficiency of replication initiation by several orders of magnitude [9]. With the replicon system it became possible, for the first time, to study efficient and genuine HCV RNA replication in vitro as well as structural aspects of the replication complex, basic replication processes, virus-host cell interactions, and antiviral agents.

In the last 6 years, a large panel of different replicon systems has been developed (Fig. 2). These include replicons from genotype 1a [19] and 2a [20], transient systems expressing easily quantifiable marker enzymes [21], replicons with green fluorescent protein (GFP) insertions in NS5A to track replication complexes in living cells [22], and full length replicons. In addition, the spectrum of permissive host cells has been expanded [23].

The replicon system revolutionized the research on basic replication processes. However, the step of infection and entry as well as the release of viral progeny could not be analysed to date. Wakita and colleagues, however, generated a genotype 2a replicon (JFH-1) that was isolated from the serum of a patient with fulminant hepatitis C [20]. This system turned out to replicate very efficiently in different cell types. Furthermore, the full-length JFH-1 sequence produced infectious viral particles that could be passaged in cell culture [15, 17]. Further, chimeric constructs with the structural region of the J6 genotype 2a clone improved the infectivity of this system significantly [16]. This recombinant infectious $\mathrm{HCV}$ cell culture system represents the last major milestone in the field and renders the complete viral life cycle accessible to detailed analysis in vitro.

\section{Cell entry}

Surrogate models for the study of the early steps of viral life cycle have been established, including infectious retroviral pseudotypes displaying functional HCV glycoproteins. These pseudotypes turned out to provide a robust model system for the study of viral entry [10, 11]. HCV pseudoparticle infectivity is pH-dependent and restricted primarily to human hepatocytes and hepatocyte-derived cell lines. Thus, HCV entry likely involves transit through an endosomal, low $\mathrm{pH}$ compartment and fusion with the endosomal membrane.

HCV E2 binds with high affinity to the large external loop of CD81, a tetraspanin found on the surface of many cell types including hepatocytes [24]. However, CD81 is not sufficient to mediate cell entry and several cofactors appear to be required. The low density lipoprotein receptor (LDLR) [25] and scavenger receptor class B type I (SR-BI) [26] have, among others, been proposed as components of a putative HCV receptor complex. The concept, that lipoproteins could play an important role for cell entry is supported by recent data from studies on HCV pseudotypes that demonstrate an enhancement of infectivity by certain components of human serum [27, 28]. In particular, association to high density lipoprotein (HDL) seems to enhance SR-BI guided cell entry and could protect viral particles from neutralizing antibodies [29]. 
Figure 2. Comparison of different replicon systems. A selection of different bicistronic and monocistronic replicon constructs including subgenomic and full-length HCV sequences is depicted schematically. Stably replicating systems are equipped among others with a neomycin phosphotransferase or a hygromycin phosphotransferase cassette that allow selection of cells with continuous RNA replication. Transient systems include a marker gene that allows quantification $48 \mathrm{~h}$ after transient transfection. In general, luciferase (Luc) is used as easily quantifiable enzyme in this context and values are normalized based on the amount of input RNA. Monocistronic replicon constructs avoid the translation of proteins from the heterologous encephalomyocarditis virus (EMCV) IRES. The resistance gene is released after cleavage via a ubiquitin sequence (Ubi).

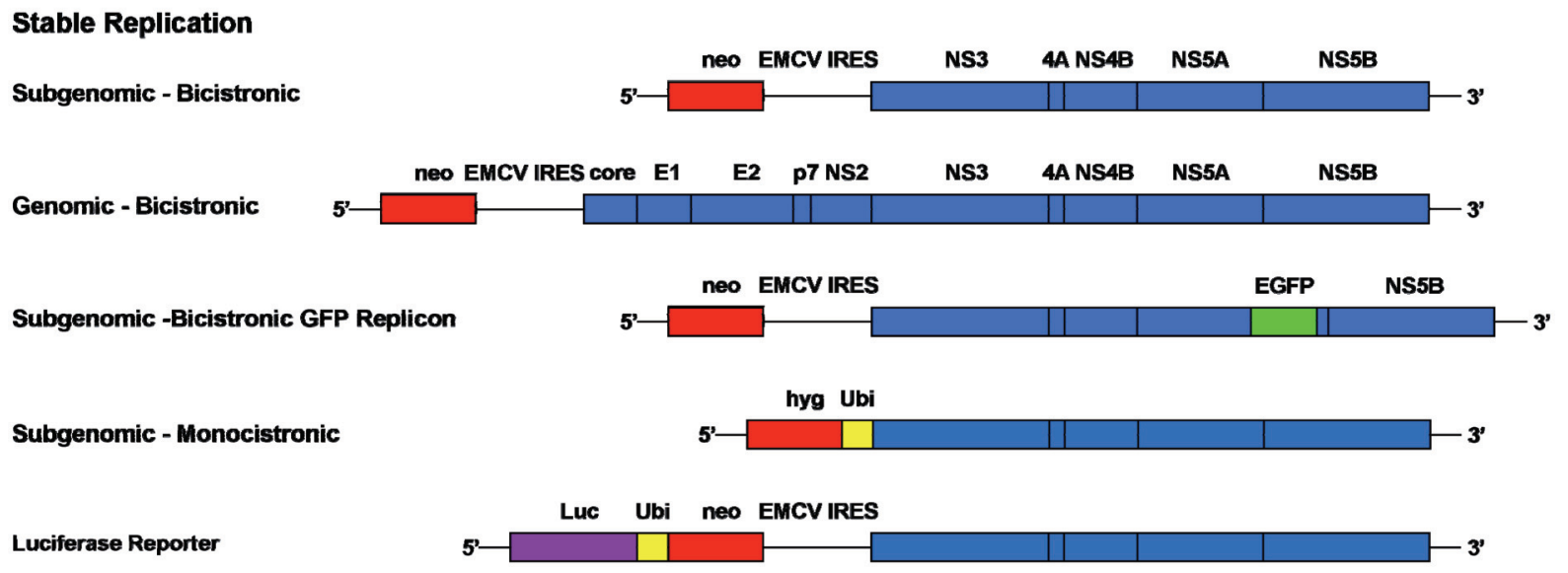

Transient Replication

Luciferase Reporter

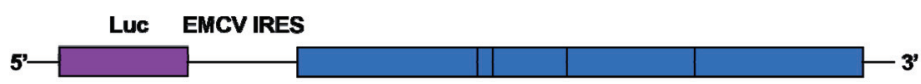

\section{Translation and polyprotein processing}

The HCV genome consists of a $9.6-\mathrm{kb}$ positive-strand RNA that comprises a long open reading frame flanked by $5^{\prime}$ and $3^{\prime}$ noncoding regions (NCR). The $5^{\prime}$ NCR is highly conserved among different HCV isolates and contains an IRES. The IRES directly binds the $40 \mathrm{~S}$ ribosomal subunit independently of the pre-initiation factors necessary for cap-dependent translation. The three-dimensional structure of the HCV IRES bound to the 40 S ribosomal subunit illustrates the molecular basis of this capindependent translation process [30]. High-resolution structural data on critical elements of the IRES and detailed characterization of the translation initiation complex further improves the view on the HCV translation initiation [31, 32].

Translation of the HCV genome leads to a polyprotein precursor that is co- and post-translationally processed by cellular and viral proteases to produce the mature structural and nonstructural proteins. The Nterminal one-third of the polyprotein harbors the structural proteins core, E1 and E2 that form the viral particle. The structural region is followed by the $p 7$ polypeptide which may be involved in ion channel formation (see below). The nonstructural proteins 2-5B coordinate viral replication by the formation of a membrane-bound replication complex. Processing of the polyprotein at the core/E1, E1/E2, E2/p7, and p7/NS2 sites by the host cell signal peptidase produces all structural proteins and p7. Two viral proteases are responsible for the maturation of the nonstructural proteins. The NS2-3 autoprotease cleaves at the NS2/NS3 junction while all downstream sites are processed by the NS3-4A serine protease.

\section{Molecular aspects of viral proteins}

\subsection{Structural proteins}

\subsubsection{Core protein}

The HCV core protein is a highly basic, RNA-binding protein which presumably forms the viral nucleocapsid. Of note, the core protein has been reported to interact with numerous cellular proteins and to affect host cell functions such as gene transcription, lipid metabolism, apoptosis and various signaling pathways [33]. Further, it has been associated with the induction of steatosis and HCC [34-36].

\subsubsection{Envelope glycoproteins}

The envelope glycoproteins E1 and E2 are type I transmembrane proteins with C-terminal hydrophobic anchors. The ectodomains translocate to the ER lumen where they are modified by extensive N-linked glycosylation. E1 and E2 form non-covalent heterodimers which are believed to represent the building blocks for the viral envelope. The processes of particle assembly and release are poorly understood and have only recently become amenable to systematic investigation. In this context, structural studies on recombinant HCV particles confirmed earlier electron microscopy observations [15].

\subsection{ARFP/F protein}

The synthesis of a protein encoded by an alternative reading frame within the core region was reported by several groups [37]. It was designated ARFP (alternative reading frame protein) or $F$ (frameshift) protein and comprises up to 160 amino acids. The ARFP/F protein is dispensable for HCV RNA replication. Whether it is expressed during natural HCV infection has still to be clarified. 


\section{$5.3 \quad p 7$}

p7 is a 63-amino acid polypeptide located at the junction between the structural and nonstructural region. It is unknown whether $\mathrm{p} 7$ is packaged into viral particles. It is composed of two transmembrane domains and has recently been reported to form hexamers with ion channel activity $[38,39]$. It is believed that $p 7$ could be important for viral assembly because the corresponding protein of the related bovine viral diarrhea virus (BVDV) is essential for the production of infectious progeny virus but not for RNA replication [40].

\section{$5.4 \quad$ Nonstructural proteins}

\subsubsection{NS2-3 autoprotease}

The NS2/3 junction is cleaved by a remarkable autoprotease consisting of NS2 and the N-terminal third of NS3. Although NS2-3 protease activity is required for the replication in vivo, it is dispensable for replication of subgenomic replicons in vitro. It is unclear whether NS2 fulfills any further functions after separation from NS3.

\subsubsection{NS3-4A}

NS3 is a multifunctional protein because it harbors a serine protease located in the N-terminal one-third that is responsible for the downstream cleavage in the nonstructural region and a NTPase/RNA helicase domain in the C-terminal two-thirds. NS4A, a 54-amino acid polypeptide, targets NS3 to intracellular membranes and is required as a cofactor for the NS3 serine protease. The crystal structure of the NS3-4A complex revealed that NS4A is an integral component of the enzyme core [41]. Surprisingly, the NS3 serine protease recently turned out to influence the innate cellular host defense by inhibition of RIG-I and TLR3 signalling [42, 43]. This observation renders the NS3 protease particularly attractive as an antiviral target [44]. Serine protease inhibitors have emerged as extremely efficient antiviral components in first 'proof-of-principle' studies in patients with chronic hepatitis C $[45,46]$.

The enzymatic activity of the NS3 NTPase/helicase activity is indispensable for RNA replication. Putative functions during replication could be to unwind replicative double strand RNA intermediates, to eliminate RNA secondary structures or to separate the genome from nucleic acid binding proteins. Recent advances in the understanding of the molecular mechanisms of this enzyme could enable a specific inhibition as a novel antiviral strategy $[47,48]$.

\subsubsection{NS4B}

Due to its very hydrophobic properties, NS4B belongs to the difficult-to-study $\mathrm{HCV}$ proteins that are poorly understood. So far, it is known that NS4B is a 27$\mathrm{kDa}$ integral membrane protein that localizes to an ERderived membranous compartment [49]. Interestingly, the expression of NS4B induces a specific membrane alteration, designated as membranous web, that serves as a scaffold for the formation of the viral replication complex [50,51].

\subsubsection{NS5A}

NS5A is a phosphorylated zinc metalloprotein of unknown function. Numerous potential functions and a huge list of interaction partners have been described [33]. However, suprisingly little efforts has been devoted to a rigorous biochemical characterization of this protein and its definitive role in viral replication remains elusive. NS5A has initially attracted considerable interest because of its potential role in modulating the IFN response (reviewed in ref. [52]). These findings are still controversial, however. A striking observation was the concentration of cell culture adaptive replicon mutations within the central part of NS5A $[9,53]$. Considering the fact that NS5A phosphorylation has an impact on replication efficiency, these observations support the concept that NS5A plays an important role in the regulation of viral replication [54-56]. The membrane association of NS5A is mediated by a unique amphipathic alpha-helix which is localized at the N-terminus [57, 58]. Limited proteolysis experiments recently allowed the definition of three protein domains within the cytosolic domain [59]. More recently, the three-dimensional structure of the $\mathrm{N}$-terminal domain I could be resolved by crystallography. After dimerization, it forms a basic groove facing the cytosol at the surface of the membrane [60]. This 'claw like' structure is believed to provide an RNA binding site that could be involved in regulated genome targeting within the replication complex.

\subsubsection{NS5B}

The key enzyme of the replicase that promotes synthesis of new RNA genomes is the NS5B RNAdependent RNA polymerase (RdRp). NS5B is a tailanchored protein, characterized by a transmembrane domain at the C-terminus of the protein responsible for posttranslational membrane targeting [61-63]. The structural organization of NS5B is a typical 'right hand' polymerase shape with finger, palm, and thumb subdomains surrounding a completely encircled active site [64]. Replication proceeds via synthesis of a complementary minus-strand RNA using the genome as a template and the subsequent synthesis of genomic plusstrand RNA from this minus-strand RNA intermediate. As central component of the HCV replicase, NS5B has emerged as a major target for antiviral intervention [44].

\section{RNA replication}

As in all positive-strand RNA viruses investigated thus far (reviewed in ref. [65]), HCV forms a membraneassociated replication complex, composed of viral proteins, replicating RNA, altered cellular membranes and additional host cell factors [50, 51]. A specific membrane alteration, referred to as the membranous web, was recently identified as the site of RNA replication in Huh-7 cells harboring subgenomic HCV replicons [51]. Thus, intracellular membranes play a crucial role in HCV replication. Recent data underline the importance of a specific lipid environment for HCV RNA replication [66, 67].

In addition to coordinated protein-protein and protein-membrane interaction, essential cis-acting replication elements (CRE) of the RNA genome were recently discovered. For instance, the sequence coding for the C-terminal domain of NS5B consists of an essential stem-loop, designated SL3.2, within a larger cruciform RNA element, designated SL3 [68]. Detailed characterization of the SL3.2 domain indicated a functionally important kissing loop interaction with the $3^{\prime}$ NCR [69].

Several host cell factors, including hVAP-A, FBL2 or cyclophylin B that influence HCV RNA replication via interaction with different viral proteins have been 
identified [54, 70, 71]. However, the regulation of replication, the switch to translation or assembly and the release of viral particles are still poorly understood.

\section{Future research directions}

The pace of research in the HCV field has increased enormously with the establishment of the replicon system. The infectious JFH-1 cell culture system promises exiting progress in the understanding of steps in the viral life cycle that have been difficult to study thus far. In particular, HCV entry, cytoplasmic release and uncoating, the initial steps of replication, virus assembly, the release of viral progeny, and the detailed virion structure will be characterized in the infectious cell culture system. Furthermore, the impact of viral proteins such as $\mathrm{p} 7$ and NS2 for viral particle formation and possibly of NS5A for the switch between replication and assembly can be explored in this context. New insights into the molecular virology of HCV should identify novel targets for antiviral strategies.

\section{Conflict of interest} exists.

The authors have declared that no conflict of interest

\section{References}

1. [No authors listed]. National Institutes of Health Consensus Development Conference Statement: Management of hepatitis C 2002 (June 10-12, 2002). Gastroenterology 2002; 123: 2082-99.

2. Manns MP, McHutchison JG, Gordon SC, Rustgi VK, Shiffman M, et al. Peginterferon alfa- $2 b$ plus ribavirin compared with interferon alfa- $2 b$ plus ribavirin for initial treatment of chronic hepatitis $C: a$ randomised trial. Lancet 2001; 358: 958-65.

3. Fried MW, Shiffman ML, Reddy KR, Smith C, Marinos G, et al. Peginterferon alfa-2a plus ribavirin for chronic hepatitis $C$ virus infection. N Engl J Med 2002; 347: 975-82.

4. Hadziyannis SJ, Sette HJr., Morgan TR, Balan V, Diago M, et al. Peginterferon-alpha2a and ribavirin combination therapy in chronic hepatitis C: a randomized study of treatment duration and ribavirin dose. Ann Intern Med 2004; 140: 346-55.

5. Muir AJ, Bornstein JD and Killenberg PG. Peginterferon alfa-2b and ribavirin for the treatment of chronic hepatitis $\mathrm{C}$ in blacks and nonHispanic whites. N Engl J Med 2004; 350: 2265-71.

6. Falck-Ytter Y, Kale H, Mullen KD, Sarbah SA, Sorescu L, et al. Surprisingly small effect of antiviral treatment in patients with hepatitis C. Ann Intern Med 2002; 136: 288-92.

7. Kolykhalov AA, Agapov EV, Blight KJ, Mihalik K, Feinstone SM, et al. Transmission of hepatitis $C$ by intrahepatic inoculation with transcribed RNA. Science 1997; 277: 570-4.

8. Lohmann V, Korner F, Koch J, Herian U, Theilmann L, et al. Replication of subgenomic hepatitis $C$ virus RNAs in a hepatoma cell line. Science 1999; 285: 110-3.

9. Blight KJ, Kolykhalov AA and Rice CM. Efficient initiation of $\mathrm{HCV}$ RNA replication in cell culture. Science 2000; 290: 1972-4.

10. Bartosch B, Dubuisson J and Cosset FL. Infectious hepatitis C virus pseudo-particles containing functional E1-E2 envelope protein complexes. J Exp Med 2003; 197: 633-42.

11. Hsu M, Zhang J, Flint M, Logvinoff C, Cheng-Mayer C, et al. Hepatitis $\mathrm{C}$ virus glycoproteins mediate $\mathrm{pH}$-dependent cell entry of pseudotyped retroviral particles. Proc Natl Acad Sci U S A 2003; 100: 7271-6.

12. Bartenschlager $R$, Frese $M$ and Pietschmann T. Novel insights into hepatitis C virus replication and persistence. Adv Virus Res 2004; 63: 71-180.

13. Penin F, Dubuisson J, Rey FA, Moradpour D and Pawlotsky JM. Structural biology of hepatitis C virus. Hepatology 2004; 39: 5-19.

14. Lindenbach BD and Rice C. Unravelling hepatitis $C$ virus replication from genome to function. Nature 2005; 436: 933-938.
15. Wakita $T$, et al. Production of infectious hepatitis $C$ virus in tissue culture from a cloned viral genome. Nature Med. 200511 :79196

16. Lindenbach BD, Evans MJ, Syder AJ, Wolk B, Tellinghuisen TL, et al. Complete replication of hepatitis $C$ virus in cell culture. Science 2005 $309: 623-26$

17. Zhong J, Gastaminza P, Cheng G, Kapadia S, Kato T, et al. Robust hepatitis C virus infection in vitro. Proc Natl Acad Sci. USA 2005102 :9294-99

18. Bartenschlager $R$. The hepatitis $C$ virus replicon system: from basic research to clinical application. J Hepatol 2005; 43: 210-6.

19. Blight $\mathrm{KJ}$, McKeating JA, Marcotrigiano J and Rice CM. Efficient replication of hepatitis $\mathrm{C}$ virus genotype 1a RNAs in cell culture. J Virol 2003; 77: 3181-90.

20. Kato T, Date T, Miyamoto M, Furusaka A, Tokushige $K$, et al. Efficient replication of the genotype 2a hepatitis $\mathrm{C}$ virus subgenomic replicon. Gastroenterology 2003; 125: 1808-17.

21. Krieger N, Lohmann V and Bartenschlager R. Enhancement of hepatitis $C$ virus RNA replication by cell culture-adaptive mutations. J Virol 2001; 75: 4614-24.

22. Moradpour D, Evans MJ, Gosert R, Yuan Z, Blum HE, et al. Insertion of green fluorescent protein into nonstructural protein $5 \mathrm{~A}$ allows direct visualization of functional hepatitis $C$ virus replication complexes. J Virol 2004; 78: 7400-9.

23. Zhu Q, Guo JT and Seeger C. Replication of hepatitis C virus subgenomes in nonhepatic epithelial and mouse hepatoma cells. J Virol 2003; 77: 9204-10.

24. Pileri P, Uematsu Y, Campagnoli S, Galli G, Falugi F, et al. Binding of hepatitis $C$ virus to CD81. Science 1998; 282: 938-41.

25. Agnello V, Abel G, Elfahal M, Knight GB and Zhang QX. Hepatitis C virus and other flaviviridae viruses enter cells via low density lipoprotein receptor. Proc Natl Acad Sci U S A 1999; 96: 12766-71.

26. Scarselli E, Ansuini H, Cerino R, Roccasecca RM, Acali S, et al. The human scavenger receptor class $\mathrm{B}$ type $\mathrm{I}$ is a novel candidate receptor for the hepatitis $C$ virus. Embo J 2002; 21: 5017-25.

27. Meunier JC, Engle RE, Faulk K, Zhao M, Bartosch B, et al. Evidence for cross-genotype neutralization of hepatitis $C$ virus pseudoparticles and enhancement of infectivity by apolipoprotein $\mathrm{C} 1$. Proc Natl Acad Sci U S A 2005; 102: 4560-5.

28. Lavillette D, Morice Y, Germanidis G, Donot P, Soulier A, et al. Human serum facilitates hepatitis $C$ virus infection, and neutralizing responses inversely correlate with viral replication kinetics at the acute phase of hepatitis $C$ virus infection. J Virol 2005; 79: 6023-34.

29. Bartosch B, Verney G, Dreux M, Donot P, Morice Y, et al. An interplay between hypervariable region 1 of the hepatitis $C$ virus E2 glycoprotein, the scavenger receptor $\mathrm{BI}$, and high-density lipoprotein promotes both enhancement of infection and protection against neutralizing antibodies. J Virol 2005; 79: 8217-29.

30. Spahn C M, Kieft JS, Grassucci RA, Penczek PA, Zhou K, et al. Hepatitis $C$ virus IRES RNA-induced changes in the conformation of the 40s ribosomal subunit. Science 2001; 291: 1959-62.

31. Kieft JS, Zhou K, Grech A, Jubin R and Doudna JA. Crystal structure of an RNA tertiary domain essential to HCV IRES-mediated translation initiation. Nat Struct Biol 2002; 9: 370-4.

32. Otto GA and Puglisi JD. The pathway of HCV IRES-mediated translation initiation. Cell 2004; 119: 369-80.

33. Tellinghuisen TL and Rice CM. Interaction between hepatitis $C$ virus proteins and host cell factors. Curr Opin Microbiol 2002; 5: 419-27.

34. Moriya K, Fujie H, Shintani Y, Yotsuyanagi H, Tsutsumi T, et al. The core protein of hepatitis $C$ virus induces hepatocellular carcinoma in transgenic mice. Nat Med 1998; 4: 1065-7.

35. Hope RG, Murphy DJ and McLauchlan J. The domains required to direct core proteins of hepatitis $C$ virus and GB virus-B to lipid droplets share common features with plant oleosin proteins. J Biol Chem 2002; 277: 4261-70.

36. Lerat H, Honda M, Beard MR, Loesch K, Sun J, et al. Steatosis and liver cancer in transgenic mice expressing the structural and nonstructural proteins of hepatitis C virus. Gastroenterology 2002; 122: 352-65.

37. Branch AD, Stump DD, Gutierrez JA, Eng F and Walewski JL. The hepatitis $C$ virus alternate reading frame (ARF) and its family of novel products: the alternate reading frame protein/F-protein, the 
double-frameshift protein, and others. Semin Liver Dis 2005; 25: 10517.

38. Griffin SD, Beales LP, Clarke DS, Worsfold O, Evans SD, et al. The p7 protein of hepatitis $C$ virus forms an ion channel that is blocked by the antiviral drug, Amantadine. FEBS Lett 2003; 535: 34-8.

39. Pavlovic D, Neville DC, Argaud O, Blumberg B, Dwek RA, et al. The hepatitis $C$ virus $p 7$ protein forms an ion channel that is inhibited by long-alkyl-chain iminosugar derivatives. Proc Natl Acad Sci U S A 2003; 100: 6104-8.

40. Harada T, Tautz N and Thiel HJ. E2-p7 region of the bovine viral diarrhea virus polyprotein: processing and functional studies. J Virol 2000; 74: 9498-506.

41. Kim JL, Morgenstern KA, Lin C, Fox T, Dwyer MD, et al. Crystal structure of the hepatitis C virus NS3 protease domain complexed with a synthetic NS4A cofactor peptide. Cell 1996; 87: 343-55.

42. Gale MJr and Foy EM. Evasion of intracellular host defence by hepatitis C virus. Nature 2005; 436: 939-45.

43. Melyan E, Curran J, Hofmann K, Moradpour D, Binder M, et al. Cardif is an adaptor protein in the RIG-I antiviral pathway and is targeted by hepatitis C virus. Nature $2005437: 1167-1172$

44. De Francesco R and Migliaccio G. Challenges and successes in developing new therapies for hepatitis $C$. Nature 2005; 436: 953-60.

45. Lamarre D, Anderson PC, Bailey M, Beaulieu P, Bolger G, et al. An NS3 protease inhibitor with antiviral effects in humans infected with hepatitis $C$ virus. Nature 2003; 426: 186-9.

46. Hinrichsen H, Benhamou Y, Wedemeyer H, Reiser M, Sentjens RE, et al. Short-term antiviral efficacy of BILN 2061, a hepatitis C virus serine protease inhibitor, in hepatitis $C$ genotype 1 patients. Gastroenterology 2004; 127: 1347-55.

47. Serebrov V and Pyle AM. Periodic cycles of RNA unwinding and pausing by hepatitis C virus NS3 helicase. Nature 2004; 430: 476-80.

48. Levin MK, Gurjar M and Patel SS. A Brownian motor mechanism of translocation and strand separation by hepatitis $C$ virus helicase. Nat Struct Mol Biol 2005; 12: 429-35.

49. Hugle T, Fehrmann F, Bieck E, Kohara M, Krausslich HG, et al. The hepatitis $\mathrm{C}$ virus nonstructural protein $4 \mathrm{~B}$ is an integral endoplasmic reticulum membrane protein. Virology 2001; 284: 70-81.

50. Egger D, Wolk B, Gosert R, Bianchi L, Blum HE, et al. Expression of hepatitis $\mathrm{C}$ virus proteins induces distinct membrane alterations including a candidate viral replication complex. J Virol 2002; 76: 5974-84.

51. Gosert R, Egger D, Lohmann V, Bartenschlager R, Blum HE, et al. Identification of the hepatitis $C$ virus RNA replication complex in Huh-7 cells harboring subgenomic replicons. J Virol 2003; 77: 548792.

52. Tan SL and Katze MG. How hepatitis $C$ virus counteracts the interferon response: the jury is still out on NS5A. Virology 2001; 284: 1-12.

53. Lohmann V, Korner F, Dobierzewska A and Bartenschlager R. Mutations in hepatitis C virus RNAs conferring cell culture adaptation. J Virol 2001; 75: 1437-49.

54. Evans MJ, Rice CM and Goff SP. Phosphorylation of hepatitis $C$ virus nonstructural protein $5 \mathrm{~A}$ modulates its protein interactions and viral RNA replication. Proc Natl Acad Sci U S A 2004; 101: 13038-43.

55. Appel N, Pietschmann $\mathrm{T}$ and Bartenschlager R. Mutational analysis of hepatitis $\mathrm{C}$ virus nonstructural protein 5A: potential role of differential phosphorylation in RNA replication and identification of a genetically flexible domain. J Virol 2005; 79: 3187-94.

56. Neddermann P, Quintavalle M, Di Pietro C, Clementi A, Cerretani $\mathrm{M}$, et al. Reduction of hepatitis C virus NS5A hyperphosphorylation by selective inhibition of cellular kinases activates viral RNA replication in cell culture. J Virol 2004; 78: 13306-14.

57. Brass V, Bieck E, Montserret R, Wolk B, Hellings JA, et al. An aminoterminal amphipathic alpha-helix mediates membrane association of the hepatitis $C$ virus nonstructural protein 5A. J Biol Chem 2002; 277: 8130-9.

58. Penin F, Brass V, Appel N, Ramboarina S, Montserret R, et al. Structure and function of the membrane anchor domain of hepatitis C virus nonstructural protein 5A. J Biol Chem 2004; 279: 40835-43.

59. Tellinghuisen TL, Marcotrigiano J, Gorbalenya AE and Rice CM. The NS5A protein of hepatitis $C$ virus is a zinc metalloprotein. J Biol Chem 2004; 279: 48576-87.
60. Tellinghuisen TL, Marcotrigiano J and Rice CM. Structure of the zinc-binding domain of an essential component of the hepatitis $\mathrm{C}$ virus replicase. Nature 2005; 435: 374-9.

61. Schmidt-Mende J, Bieck E, Hugle T, Penin F, Rice CM, et al. Determinants for membrane association of the hepatitis $\mathrm{C}$ virus RNA-dependent RNA polymerase. J Biol Chem 2001; 276: 44052-63.

62. Ivashkina N, Wolk B, Lohmann V, Bartenschlager R, Blum HE, et al. The hepatitis $C$ virus RNA-dependent RNA polymerase membrane insertion sequence is a transmembrane segment. J Virol 2002; 76: 13088-93.

63. Moradpour D, Brass V, Bieck E, Friebe P, Gosert R, et al. Membrane association of the RNA-dependent RNA polymerase is essential for hepatitis C virus RNA replication. J Virol 2004; 78: 13278-84.

64. Lesburg CA, Cable MB, Ferrari E, Hong Z, Mannarino AF, et al. Crystal structure of the RNA-dependent RNA polymerase from hepatitis $C$ virus reveals a fully encircled active site. Nat Struct Biol 1999; 6: 937-43.

65. Ahlquist P, Noueiry AO, Lee WM, Kushner DB and Dye BT. Host factors in positive-strand RNA virus genome replication. J Virol 2003; 77: 8181-6.

66. Ye J, Wang C, Sumpter RJr., Brown MS, Goldstein JL, et al. Disruption of hepatitis $C$ virus RNA replication through inhibition of host protein geranylgeranylation. Proc Natl Acad Sci U S A 2003; 100: 15865-70.

67. Kapadia SB and Chisari FV. Hepatitis C virus RNA replication is regulated by host geranylgeranylation and fatty acids. Proc Natl Acad Sci U S A 2005; 102: 2561-6.

68. You S, Stump DD, Branch AD and Rice CM. A cis-acting replication element in the sequence encoding the NS5B RNA-dependent RNA polymerase is required for hepatitis $C$ virus RNA replication. J Virol 2004; 78: 1352-66.

69. Friebe P, Boudet J, Simorre JP and Bartenschlager R. Kissing-loop interaction in the $3^{\prime}$ end of the hepatitis $C$ virus genome essential for RNA replication. J Virol 2005; 79: 380-92.

70. Wang C, Gale MJr., Keller BC, Huang H, Brown MS, et al. Identification of FBL2 as a geranylgeranylated cellular protein required for hepatitis C virus RNA replication. Mol Cell 2005; 18: 425-34.

71. Watashi K, Ishii N, Hijikata M, Inoue D, Murata T, et al. Cyclophilin $\mathrm{B}$ is a functional regulator of hepatitis $\mathrm{C}$ virus RNA polymerase. Mol Cell 2005; 19: 111-22.

\section{Author biography}

Hubert E. Blum, MD, is the chairman of the Department of Gastroenterology and Hepatology, University Hospital Freiburg, Germany. His research focus includes molecular biology and immunology of viral hepatitis $B$ and $C$ as well as basic and clinical aspects of gastrointestinal malignancies, especially hepatocellular and colorectal carcinoma.

Darius Moradpour, MD, was Assistant Professor of Medicine and Staff Physician at the Department of Gastroenterology and Hepatology, University Hospital Freiburg, Germany. Since 2004 he is the head of the Division of Gastroenterology and Hepatology, Centre Hospitalier Universitaire Vaudois Lausanne, Switzerland. His scientific work includes the molecular virology and pathogenesis of the hepatitis $C$ virus infection.

Volker Brass, MD, is resident at the Department of Gastroenterology and Hepatology, University Hospital Freiburg, Germany. Together with Hubert E. Blum and Darius Moradpour, he works on the molecular virology of the hepatitis C virus. 